\title{
Physical activity, sedentary behaviours and dietary habits among Kuwaiti adolescents: gender differences
}

\author{
Ahmad Allafi ${ }^{1}$, Ahmad R Al-Haifi ${ }^{2}$, Mohammad A Al-Fayez ${ }^{2}$, Buthaina I Al-Athari ${ }^{2}$, \\ Fahhad A Al-Ajmi ${ }^{2}$, Hazzaa M Al-Hazzaa ${ }^{3}$, Abdulrahman O Musaiger ${ }^{4}$ and \\ Faruk Ahmed ${ }^{5, *}$ \\ 'Department of Family Sciences, College for Women, Kuwait University, Safat, Kuwait: ${ }^{2}$ Food and Nutrition Science, \\ College of Health Sciences, Showaikh, Kuwait: ${ }^{3}$ Pediatric Exercise Physiology Research Laboratory, College of \\ Education, King Saud University, Riyadh, Saudi Arabia: ${ }^{4}$ Arab Nutrition Center, Manama and Nutrition and Health \\ Studies Unit, Deanship of Scientific Research, University of Bahrain, Manama, Bahrain: ${ }^{5}$ Nutrition and Dietetics, \\ School of Public Health and Griffith Health Institute, Griffith University, Gold Coast Campus, QLD 4222, Australia
}

Submitted 28 February 2013: Final revision received 11 June 2013: Accepted 23 July 2013: First published online 30 August 2013

\begin{abstract}
Objective: The present study was designed to assess physical activity, sedentary behaviours and dietary habits among adolescents in Kuwait and to compare the differences between genders.

Design: A cross-sectional study was conducted among secondary-school children who participated in the Arab Teens Lifestyle Study (ATLS), a multi-centre collaborative project.

Setting: Secondary schools in Kuwait.

Subjects: Adolescents (463 boys and 443 girls), aged 14-19 years.

Results: Nearly half $(44 \cdot 6 \%)$ of the boys and three-quarters $(76 \cdot 0 \%)$ of the girls did not meet the recommended daily physical activity levels ( $\geq 2520$ MET-min/week, moderate to vigorous intensity). Nearly all (96.3\% of boys and $96 \cdot 7 \%$ of girls) adolescents reported spending $>2 \mathrm{~h} / \mathrm{d}$ on screen time, with girls found to spend more time per day watching television $(P=0 \cdot 02)$ and using a computer $(P<0 \cdot 001)$. The large majority of the adolescents reported skipping breakfast and not having milk and milk products, vegetables and fruit daily, while nearly two-thirds of the boys and girls had sugar-sweetened drinks on more than $3 \mathrm{~d} /$ week. Compared with girls, boys reported consuming more fruit $(3 \cdot 4 v .2 \cdot 8$ times/week, $P=0 \cdot 001)$, dairy products $(4.5 v .3 .6$ times/week, $P=0.001)$ and energy drinks $(1.3 v$. $1 \cdot 1$ times/week, $P=0 \cdot 003)$.

Conclusions: The majority of the Kuwaiti adolescents, especially girls, do not perform adequate physical activity, spend more time on sedentary activities and have unhealthy dietary practices. The findings emphasize an urgent need for implementing an appropriate intervention for promoting physical activity, healthy eating and reducing sedentary behaviours among these children.
\end{abstract}

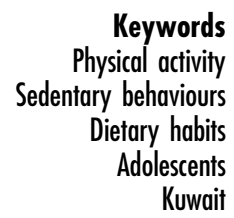

Over the past few decades, the prevalence of overweight and obesity among children and adolescents has increased at an alarming rate in many parts of the world ${ }^{(1)}$. While many of the health problems associated with obesity were previously thought of as diseases of adults only, childhood obesity is now well recognized as a major public health problem. Studies have shown that children and adolescents who are obese are at greater risk for bone and joint problems, sleep apnoea, and social and psychological problems compared with their normal-weight peers ${ }^{(2-4)}$. Childhood obesity has also been found to be associated with cardiovascular risk factors such as hypertension, dyslipidaemias, diabetes and metabolic syndrome ${ }^{(5-8)}$. Moreover, studies have shown that children and adolescents who are obese are likely to be obese as adults ${ }^{(9)}$ and are more at risk for adult health problems such as heart disease, type 2 diabetes, stroke, several types of cancer and osteoarthritis ${ }^{(10,11)}$.

Kuwait has one of the highest obesity rates in the world. A recent report of the Kuwait National Nutrition Surveillance System indicated that the overall prevalence of overweight and obesity among adolescent children, aged 10-19 years, ranged from $41 \cdot 1$ to $54 \cdot 4 \%{ }^{(12)}$. Furthermore, compared with boys, the report showed a higher prevalence of overweight and a lower prevalence of obesity among girls. Evidence suggests that the worldwide increase in overweight and obesity is largely due to modifiable lifestyle factors such as decreased physical 
activity, eating out, and increased consumption of energydense foods with high saturated fat and refined carbohydrates ${ }^{(13-15)}$. In Kuwait, a rapid increase in economic uplift and urbanization has been accompanied by profound changes in lifestyle, such as replacement of traditional diets of vegetables, fruits and wholegrain products with fast foods and sugar-sweetened beverages along with decreased levels of physical activity in all population groups ${ }^{(16,17)}$. The most recent report of the National Nutrition Surveillance System indicated that excessive consumption of energy, soft drinks and fast foods, frequent snacking and lack of physical activity are the major risk factors for overweight and obesity among Kuwaiti children ${ }^{(12)}$.

Adolescence is an important stage of life when lifestyle behaviours including dietary habits are formed and become established. The lifestyle behaviour patterns that are established during early years can have important implications on health and well-being. Further, both physical exercise and food intake patterns of adolescents tend to differ according to gender ${ }^{(18,19)}$. Recently we have reported that in boys physical activity explained a greater proportion of variation in BMI than their eating habits, while for girls it was their eating habits that explained the greater proportion of variation in $\mathrm{BMI}^{(20)}$. Understanding the gender differences in lifestyle-related risk factors of overweight and obesity among Kuwaiti adolescents is crucial for devising public health policies and effective strategies to prevent and treat childhood obesity. Despite these major considerations, there have been no systematic studies among Kuwaiti adolescent children to characterize their physical activity, sedentary behaviours and dietary habits simultaneously. The present study reports on the physical activity, sedentary behaviours and dietary habits of adolescent children in Kuwait and presents gender differences by using a research paradigm which was carried out in other parts of the Middle East.

\section{Participants and methods}

The present study is part of the Arab Teens Lifestyle Survey (ATLS), which is a school-based, cross-sectional, multicentre collaborative study in the Arabian Peninsula ${ }^{(21,22)}$. The study protocol was approved by the Public Authority for Applied Education and Training, the Ministry of Education and school principals in Kuwait. Informed consent was obtained from the parents of each participant. Data were collected by trained researchers under the supervision of the lead author. The participants filled in the ATLS questionnaire in their classrooms in the presence of their teachers and at least one research assistant.

\section{Study participants}

The study group comprised 906 children (463 boys and 443 girls), aged 14-19 years, who were students of grades 10 to 12 in secondary schools in Kuwait. A multistage stratified random sampling technique was used to obtain the sample. In the first stage, schools were selected using a systematic random sampling procedure. The schools were stratified into public and private schools and further stratified on the basis of boys' and girls' secondary schools. Two public schools from each of the six Governorates were chosen (one from the boys' and one from the girls' schools). The selection of the private and public schools was proportional to size and thus two private schools were selected. At the second stage, using a simple random sampling technique, one class from each of the three grades (10, 11 and 12) per school was selected. A total of thirty-six classes from public schools and six classes from private schools were selected, which included an average twenty-five students from each class. The study samples represent $8 \%$ of the total number of secondary-school children. All levels of education are free for Kuwaitis, and therefore the rate of dropping out from school is extremely low. All students in the selected classes who were free from any physical health problems (physical challenge to perform physical activity) were invited to participate in the study. Data were collected during October to December 2009.

\section{Data collection}

\section{Anthropometric measurements}

Body weight of each participant was measured to the nearest $100 \mathrm{~g}$ using a calibrated portable scale (DETECTO Scale Co., Webb City, MO, USA). Measurements were done with the participant in minimal clothing without shoes. Height was measured to the nearest centimetre using a calibrated measuring rod (DETECTO Scale Co.) while the participant was in full standing position. BMI was calculated as a ratio of weight in kilograms by the square of height in metres. The International Obesity Taskforce age- and sex-specific BMI cut-off reference standards ${ }^{(23)}$ were used to identify overweight and obesity in adolescents between the ages of 14 and 17 years. For participants aged 18 years and above, the WHO adult cut-off points ${ }^{(24)}$ were used. All measurements were performed in the morning.

\section{Physical activity assessment}

A validated self-report questionnaire (ATLS) was used to assess the adolescents' physical activity patterns and sedentary behaviours. Details of the validation of the physical activity questionnaire and data collection procedure have been described elsewhere ${ }^{(20,21)}$. The questionnaire was designed to collect information on frequency, duration and intensity of a variety of light-, moderate- and vigorous-intensity physical activities during a typical week. The physical activity questionnaire covered all domains of physical activity such as transport and household, fitness and sports activities. Physical activities were assigned metabolic equivalent of task 
(MET) values based on the compendium of physical activity $^{(25)}$ and the compendium of physical activity for youth $^{(26)}$ as described in detail elsewhere ${ }^{(20)}$. Briefly, the moderate-intensity physical activity includes activities such as normal-pace walking, brisk walking, recreational swimming, household activities and moderate-intensity recreational sports such as volleyball, badminton and table tennis. Moderate-intensity recreational sports were assigned an average MET value equivalent to 4 MET. Vigorous-intensity physical activity and sports include stair-climbing, jogging, running, cycling, self-defence, weight training, and vigorous sports such as soccer, basketball, handball and singles tennis. Vigorous-intensity sports were assigned a value equivalent to 8 MET. The total amount of exercise per week was then expressed in MET-min/week using 4 and 8 MET for moderate- and vigorous-intensity activities, respectively.

The proportion of adolescents who met the daily physical activity recommendations was calculated by using two different MET-min cut-off scores ${ }^{(27,28)}$ : (i) moderate-intensity physical activity of $1 \mathrm{~h} / \mathrm{d}$, corresponding to a total of $1680 \mathrm{MET}-\mathrm{min} /$ week $(60 \mathrm{~min} / \mathrm{d} \times 7 \mathrm{~d} /$ week $\times 4 \mathrm{MET})$; and (ii) moderate- to vigorous-intensity physical activity of $1 \mathrm{~h} / \mathrm{d}$, which corresponds to a total of 2520 MET-min/week $(60 \mathrm{~min} / \mathrm{d} \times 7 \mathrm{~d} /$ week $\times 6 \mathrm{MET})$.

\section{Sedentary behaviours}

To evaluate the sedentary behaviours of the participants, information on the amount of time spent watching television (TV), playing video and computer games, and Internet use was collected. Participants were asked to provide average number of daily hours spent for each of the activities without differentiating between weekdays and weekends. For the total screen time cut-off point, we used the American Academy of Pediatrics' guidelines of a maximum of $2 \mathrm{~h} / \mathrm{d}^{(29)}$.

\section{Eating habits}

A separate section of the ALTS questionnaire consisting of ten questions was used to assess certain dietary habits (healthy and unhealthy) of the participants. Information on the frequency of consumption of selected food items was collected. The questions included those related to how many times per typical week the participant consumed breakfast, vegetables (cooked and uncooked), fruit, milk and dairy products, doughnuts and cakes, candies and chocolates, energy drinks, sugar-sweetened drinks including soft beverages and fast foods. The fast foods included examples of both Western fast foods and Arabic fast-food choices such as Shawarma (grilled meat or chicken in pita bread with some salad). The students had a choice of answers, ranging from zero intakes to a maximum intake of $7 \mathrm{~d}$ /week (every day). Healthy dietary habits were defined when breakfast, fruit, vegetables and milk were consumed daily ( $7 \mathrm{~d} /$ week), while unhealthy dietary habits were defined when doughnuts and cakes, candies and chocolates, energy drinks, sugarsweetened drinks and fast foods were consumed on more than $3 \mathrm{~d} /$ week.

\section{Statistical analysis}

Univariate analysis comprised of simple frequency distribution of selected variables. For each of the variables, a normality test for distribution of the data was performed using the Kolmogorv-Smirnov goodness-of-fit test. The data for all dependent variables were skewed and thus appropriate data transformations were done during analysis. To examine the differences between genders in anthropometry, physical activity, sedentary behaviours and dietary habits, generalized linear mixed-effect models were performed to take into account of the multilevel sampling effect (Governorate and school type) on each of the dependent variables. The data are presented as adjusted means along with 95\% confidence intervals in relation to various dependent variables. Further, the proportion of male and female adolescents who exceeded the specific cut-off scores for various physical activity levels, sedentary activities and dietary parameters was calculated. The $\chi^{2}$ test was performed for these proportions to examine the differences between genders. A $P$ value of 0.05 or less was considered statistically significant. Data were analysed using the statistical software package IBM SPSS Statistics $20 \cdot 0$.

\section{Results}

Of the 906 participants, there were slightly more boys $(51 \cdot 1 \%)$ than girls $(48.9 \%)$. There was no significant difference between boys and girls in mean age (Table 1 ). Overall, boys were significantly taller and heavier than girls (both $P=0 \cdot 001$ ). However, there was no significant difference in BMI between boys and girls.

Table 2 shows the sedentary behaviours and physical activity patterns of Kuwaiti adolescent boys and girls. Overall, the level of physical activity differed significantly between genders (most $P=0 \cdot 001$ ); on average boys were more physically active with more bouts of moderate- and vigorous-intensity activities than girls. The total MET-min score per week was significantly $(P=0 \cdot 001)$ higher in boys than in girls. A significantly $(P=0 \cdot 001)$ higher proportion of boys $(55 \cdot 6 \%)$ than girls $(24 \cdot 0 \%)$ met the recommended moderate- to vigorous-intensity physical activity level of $1 \mathrm{~h} / \mathrm{d}$ ( $\geq 2520 \mathrm{MET}-\mathrm{min} /$ week).

Compared with boys, girls spent more time watching TV $(P=0.024)$ and working/playing on a computer $(P=0 \cdot 001)$. The mean sleep duration was not significantly different between the genders. Although the proportion of girls spending more than the recommended screen time guidelines $(\leq 2 \mathrm{~h} / \mathrm{d})$ was similar to that of boys, significantly more girls than boys were spending $>2 \mathrm{~h} / \mathrm{d}$ on computer-related activities $(P=0 \cdot 014)$. 
Table 1 Characteristics of the study participants by gender: Kuwaiti adolescents aged 14-19 years, Arab Teens Lifestyle Survey (ATLS), October-December 2009

\begin{tabular}{|c|c|c|c|c|c|c|c|}
\hline \multirow[b]{2}{*}{ Variable } & \multicolumn{3}{|c|}{ Males (n 463) } & \multicolumn{3}{|c|}{ Females (n 443) } & \multirow[b]{2}{*}{$P$ value* } \\
\hline & Mean & $95 \% \mathrm{Cl}$ & $\%$ & Mean & $95 \% \mathrm{Cl}$ & $\%$ & \\
\hline Age (year) & $16 \cdot 3$ & $16 \cdot 1,16 \cdot 4$ & - & $16 \cdot 2$ & $16 \cdot 0,16 \cdot 3$ & - & $0 \cdot 129$ \\
\hline Weight (kg) & $72 \cdot 9$ & $71 \cdot 3,74 \cdot 5$ & - & $62 \cdot 2$ & $60 \cdot 7,63 \cdot 8$ & - & 0.001 \\
\hline Height (cm) & $169 \cdot 3$ & $168 \cdot 5,170 \cdot 0$ & - & $157 \cdot 4$ & $156 \cdot 7,158 \cdot 2$ & - & 0.001 \\
\hline BMI $\left(\mathrm{kg} / \mathrm{m}^{2}\right)$ & $25 \cdot 3$ & $24 \cdot 7,25 \cdot 8$ & - & $25 \cdot 1$ & $24 \cdot 5,25 \cdot 7$ & - & 0.714 \\
\hline Overweight (\%) & - & - & $25 \cdot 1$ & - & - & $25 \cdot 3$ & \\
\hline Obese (\%) & - & - & $25 \cdot 5$ & - & - & $21 \cdot 3$ & \\
\hline
\end{tabular}

*Generalized linear-mixed effect model.

Table 2 Physical activity measures and sedentary behaviours by gender: Kuwaiti adolescents aged 14-19 years, Arab Teens Lifestyle Survey (ATLS), October-December 2009

\begin{tabular}{|c|c|c|c|c|c|c|c|}
\hline \multirow[b]{2}{*}{ Variable } & \multicolumn{3}{|c|}{ Males ( $n$ 463) } & \multicolumn{3}{|c|}{ Females ( $n$ 443) } & \multirow[b]{2}{*}{$P$ value } \\
\hline & Mean & $95 \% \mathrm{Cl}$ & $\%$ & Mean & $95 \% \mathrm{Cl}$ & $\%$ & \\
\hline \multicolumn{8}{|l|}{ Physical activity measures } \\
\hline Moderate activity (h/week) & $3 \cdot 8$ & $3 \cdot 4,4 \cdot 3$ & - & $2 \cdot 9$ & $2 \cdot 4,3 \cdot 3$ & - & 0.001 \\
\hline Moderate activity (MET-min/week) & $1031 \cdot 7$ & $978 \cdot 5,1084 \cdot 9$ & - & $878 \cdot 0$ & $824 \cdot 7,931 \cdot 2$ & - & $0 \cdot 001$ \\
\hline Vigorous activity (h/week) & $4 \cdot 0$ & $1 \cdot 2,13 \cdot 5$ & - & $0 \cdot 12$ & $0 \cdot 01,1 \cdot 20$ & - & 0.006 \\
\hline Vigorous activity (MET-min/week) & $2626 \cdot 1$ & $2367 \cdot 0,2913 \cdot 5$ & - & $998 \cdot 9$ & $900 \cdot 3,1108 \cdot 2$ & - & $0 \cdot 001$ \\
\hline Total MET-min/weekt & $3708 \cdot 0$ & $3429 \cdot 5,4009 \cdot 1$ & - & $1865 \cdot 5$ & $1725 \cdot 4,2016 \cdot 9$ & - & $0 \cdot 001$ \\
\hline$\geq 1680$ MET-min/week (\%) & - & - & $70 \cdot 5$ & - & - & $39 \cdot 2$ & $0.001 \S$ \\
\hline$\geq 2520$ MET-min/week (\%) & - & - & $55 \cdot 6$ & - & - & $24 \cdot 0$ & $0.001 \S$ \\
\hline \multicolumn{8}{|l|}{ Sedentary behaviours } \\
\hline TV viewing $(\mathrm{h} / \mathrm{d})$ & $3 \cdot 6$ & $3 \cdot 4,3 \cdot 8$ & - & $3 \cdot 9$ & $3 \cdot 7,4 \cdot 1$ & - & 0.024 \\
\hline TV viewing $>2 \mathrm{~h} / \mathrm{d}(\%)$ & - & - & $69 \cdot 7$ & - & - & $72 \cdot 7$ & NS§ \\
\hline Computer use $(\mathrm{h} / \mathrm{d})$ & $3 \cdot 6$ & $3 \cdot 3,3 \cdot 8$ & - & $4 \cdot 1$ & $3 \cdot 9,4 \cdot 4$ & - & 0.001 \\
\hline Computer use $>2 \mathrm{~h} / \mathrm{d}(\%)$ & - & - & $62 \cdot 1$ & - & - & $70 \cdot 0$ & $0 \cdot 014 \S$ \\
\hline Total sedentary activity $(\mathrm{h} / \mathrm{d}) \ddagger$ & $7 \cdot 2$ & $6 \cdot 9,7 \cdot 5$ & - & $8 \cdot 0$ & $7 \cdot 7,8 \cdot 3$ & - & $0 \cdot 001$ \\
\hline Total sedentary activity $>2 \mathrm{~h} / \mathrm{d}(\%)$ & - & - & $96 \cdot 3$ & - & - & $96 \cdot 7$ & NS\$ \\
\hline Sleeping $(h / d)$ & $5 \cdot 2$ & $5 \cdot 1,5 \cdot 4$ & - & $5 \cdot 1$ & $4 \cdot 9,5 \cdot 2$ & - & NS \\
\hline Sleeping $<7 \mathrm{~h} / \mathrm{d}(\%)$ & - & - & $76 \cdot 1$ & - & - & $74 \cdot 2$ & NS§ \\
\hline
\end{tabular}

MET, metabolic equivalent of task; TV, television.

${ }^{*}$ Generalized linear-mixed effect model, except where noted otherwise.

tCombined moderate- and vigorous-intensity activities.

‡Combined TV viewing and computer use.

$\S \chi^{2}$ test.

Table 3 presents the food habits of the Kuwaiti adolescent children expressed as mean frequency of days of intake per week and the distribution of the participants by frequency of days of intake per week. Overall, the most consumed food item observed was sugar-sweetened drinks: 4.8 and 4.5 times/week for boys and girls, respectively. On the other hand, the least consumed food item was energy drinks: $1 \cdot 3$ and $1 \cdot 1$ times/week for boys and girls, respectively. Compared with girls, boys reported consuming significantly more vegetables $(P=0 \cdot 02)$, fruits $(P=0 \cdot 001)$, dairy products $(P=0 \cdot 001)$ and energy drinks $(P=0 \cdot 003)$. On the other hand, girls had significantly higher consumption of cakes/doughnuts $(P=0 \cdot 001)$ and sweets $(P=0 \cdot 001)$ than boys. There were no significant gender differences in the frequency of consumption of sugar-sweetened drinks, fast foods and potato chips.

Relatively more boys than girls consumed breakfast $(27 \cdot 8 \% v \cdot 18 \cdot 0 \%)$, milk and milk products $(36 \cdot 3 \% v \cdot 25 \cdot 3 \%)$, vegetables $(26 \cdot 0 \% v \cdot 22 \cdot 1 \%)$ and fruit $(17 \cdot 5 \% v \cdot 11 \cdot 8 \%)$ daily. About two-thirds of the boys (66\%) and girls (60\%) had sugar-sweetened drinks on more than $3 \mathrm{~d} /$ week. Relatively smaller proportions of both boys $(14 \cdot 0 \%)$ and girls $(12 \cdot 7 \%)$ had energy drinks on more than $3 \mathrm{~d} /$ week. Relatively more girls than boys consumed cakes/doughnuts $(32 \cdot 9 \% v .26 \cdot 8 \%)$ and sweets $(64 \cdot 7 \% v .50 \cdot 3 \%)$ on more than $3 \mathrm{~d} /$ week.

\section{Discussion}

The present cross-sectional study reports on the physical activity level, sedentary behaviours and dietary habits of adolescent children in Kuwait. We are not aware of any other study that has characterized lifestyle behaviours including dietary habits of this population using a validated questionnaire that was comprehensive enough to gather information about physical activity patterns in 
Table 3 Food habits by gender: Kuwaiti adolescents aged 14-19 years, Arab Teens Lifestyle Survey (ATLS), October-December 2009

\begin{tabular}{|c|c|c|c|c|c|c|c|c|c|}
\hline \multirow[b]{2}{*}{ Food item } & \multirow[b]{2}{*}{ Gender } & \multicolumn{4}{|c|}{ Frequency/week } & \multicolumn{4}{|c|}{ Frequency/week } \\
\hline & & $n$ & Mean & $95 \% \mathrm{Cl}$ & $P$ value* & Never (\%) & $1-3(\%)$ & 4-6 (\%) & $\geq 7(\%)$ \\
\hline \multirow[t]{2}{*}{ Breakfast } & Males & 460 & $3 \cdot 6$ & $3 \cdot 2,3 \cdot 9$ & 0.001 & $18 \cdot 0$ & $35 \cdot 3$ & $18 \cdot 9$ & $27 \cdot 8$ \\
\hline & Females & 438 & $3 \cdot 1$ & $2 \cdot 7,3 \cdot 4$ & & $21 \cdot 7$ & $38 \cdot 6$ & $21 \cdot 7$ & $18 \cdot 0$ \\
\hline \multirow[t]{2}{*}{ Milk and milk products } & Males & 457 & $4 \cdot 5$ & $4 \cdot 3,4 \cdot 7$ & 0.001 & $5 \cdot 7$ & $33 \cdot 3$ & $24 \cdot 7$ & $36 \cdot 3$ \\
\hline & Females & 434 & $3 \cdot 6$ & $3 \cdot 4,3 \cdot 8$ & & $14 \cdot 3$ & $39 \cdot 4$ & $21 \cdot 0$ & $25 \cdot 3$ \\
\hline \multirow[t]{2}{*}{ Vegetables } & Males & 458 & $3 \cdot 8$ & $3 \cdot 6,4 \cdot 0$ & 0.02 & $10 \cdot 5$ & $37 \cdot 5$ & $26 \cdot 0$ & $26 \cdot 0$ \\
\hline & Females & 435 & $3 \cdot 5$ & $3 \cdot 3,3 \cdot 7$ & & $10 \cdot 6$ & $45 \cdot 0$ & $22 \cdot 3$ & $22 \cdot 1$ \\
\hline \multirow[t]{2}{*}{ Fruits } & Males & 458 & $3 \cdot 4$ & $3 \cdot 2,3 \cdot 5$ & 0.001 & $8 \cdot 7$ & $50 \cdot 7$ & $23 \cdot 1$ & $17 \cdot 5$ \\
\hline & Females & 434 & $2 \cdot 8$ & $2 \cdot 7,3 \cdot 0$ & & $14 \cdot 3$ & $53 \cdot 7$ & $20 \cdot 2$ & $11 \cdot 8$ \\
\hline \multirow[t]{2}{*}{ Fast foods } & Males & 458 & $3 \cdot 0$ & $2 \cdot 8,3 \cdot 1$ & $0 \cdot 30$ & $7 \cdot 0$ & $60 \cdot 9$ & $22 \cdot 7$ & $9 \cdot 4$ \\
\hline & Females & 434 & $2 \cdot 8$ & $2 \cdot 7,3 \cdot 0$ & & $5 \cdot 1$ & $68 \cdot 2$ & $16 \cdot 3$ & $10 \cdot 4$ \\
\hline \multirow[t]{2}{*}{ Potato chips (French fries) } & Males & 456 & $3 \cdot 1$ & $2 \cdot 9,3 \cdot 2$ & 0.36 & $10 \cdot 3$ & $52 \cdot 4$ & $27 \cdot 9$ & $9 \cdot 4$ \\
\hline & Females & 436 & $3 \cdot 2$ & $3 \cdot 0,3 \cdot 4$ & & $6 \cdot 7$ & $58 \cdot 2$ & $22 \cdot 7$ & $12 \cdot 4$ \\
\hline \multirow[t]{2}{*}{ Cakes/doughnuts } & Males & 459 & $2 \cdot 5$ & $2 \cdot 3,2 \cdot 7$ & 0.001 & $15 \cdot 3$ & $58 \cdot 0$ & $19 \cdot 8$ & $7 \cdot 0$ \\
\hline & Females & 435 & $3 \cdot 0$ & $2 \cdot 8,3 \cdot 2$ & & $10 \cdot 8$ & $56 \cdot 3$ & $18 \cdot 2$ & $14 \cdot 7$ \\
\hline \multirow[t]{2}{*}{ Sweats } & Males & 459 & $3 \cdot 8$ & $3 \cdot 6,4 \cdot 0$ & 0.001 & $6 \cdot 8$ & $42 \cdot 9$ & $29 \cdot 2$ & $21 \cdot 1$ \\
\hline & Females & 435 & $4 \cdot 6$ & $4 \cdot 3,4 \cdot 8$ & 0.0001 & $4 \cdot 8$ & $31 \cdot 5$ & $28 \cdot 1$ & $35 \cdot 6$ \\
\hline \multirow[t]{2}{*}{ Sugar-sweetened drinks } & Males & 460 & $4 \cdot 8$ & $4 \cdot 5,5 \cdot 0$ & 0.08 & $4 \cdot 6$ & $29 \cdot 5$ & $23 \cdot 7$ & $42 \cdot 2$ \\
\hline & Females & 437 & $4 \cdot 5$ & $4 \cdot 3,4 \cdot 8$ & & $5 \cdot 5$ & $34 \cdot 6$ & $22 \cdot 4$ & $37 \cdot 5$ \\
\hline \multirow[t]{2}{*}{ Energy drinks } & Males & 459 & $1 \cdot 3$ & $1 \cdot 2,1 \cdot 5$ & 0.003 & $51 \cdot 6$ & $34 \cdot 0$ & $9 \cdot 0$ & $5 \cdot 4$ \\
\hline & Females & 434 & $1 \cdot 1$ & $0.07,0.94$ & & $68 \cdot 4$ & $18 \cdot 9$ & $6 \cdot 2$ & $6 \cdot 5$ \\
\hline
\end{tabular}

*Generalized linear-mixed effect model.

terms of frequency, duration and intensity by transcribing it to a MET-min scale. The study revealed a number of important findings: (i) nearly half of the boys $(44 \cdot 4 \%)$ and three-quarters $(76.0 \%)$ of the girls do not meet the current global recommendation for physical activity; (ii) virtually all ( $>95 \%$ ) of the boys and girls spend more than $2 \mathrm{~h} / \mathrm{d}$ on sedentary activities; (iii) over two-thirds of these children do not eat breakfast daily and about a quarter never have breakfast; and (iv) a significant proportion of these children have an unhealthy dietary pattern.

Overall, the prevalence of overweight and obesity in boys and girls was $50.5 \%$ and $46.5 \%$, respectively. This finding is very similar to what was reported for Kuwaiti adolescent children, aged 15-19 years, in the most recent National Nutrition Surveillance System report ${ }^{(12)}$. A recent review on the prevalence of overweight and obesity indicated the highest prevalence of overweight and obesity among Kuwaiti adolescents in the Eastern Mediterranean region ${ }^{(30)}$. While boys were significantly taller and heavier than girls, there was no statistically significant difference in mean BMI or in prevalence of overweight or obesity between boys and girls. On the contrary, Saudi adolescent boys had significantly higher BMI than girls ${ }^{(21)}$; however, there was no information on the prevalence of overweight and obesity in those children.

The present study used two different cut-off scores to define physically active. Using the lower cut-off score of $1680 \mathrm{MET}-\mathrm{min} /$ week (equivalent to moderate activities of $1 \mathrm{~h} / \mathrm{d}$ ) which was considered performing recommended physical activity ${ }^{(27)}$, about $70 \%$ of the boys and $39 \%$ of the girls were found to be physically active. In contrast, slightly over half of the boys and less than a quarter of the girls in Saudi Arabia met this recommendation ${ }^{(21)}$. Another cross-cultural study reported that over $80 \%$ of the adolescent boys and over $60 \%$ of the girls in the UK met the recommended moderate-intensity physical activity level of $60 \mathrm{~min} / \mathrm{d}^{(31)}$. Recently it has been recommended by the WHO that adolescents should participate in moderate- to vigorous-intensity activities for at least $1 \mathrm{~h} / \mathrm{d}$ ( $\geq 2520 \mathrm{MET}$-min/week) to ensure health benefit ${ }^{(28)}$. Using this higher cut-off for recommended physical activity level ( $\geq 2520$ MET-min/week), nearly half $(45 \%)$ of the boys and three-quarters $(76 \%)$ of the girls were found not to be performing adequate daily physical activity and thus indicating a high prevalence of physical inactivity among Kuwaiti adolescent children, especially among girls. Based on average MET-min/week of both the moderate and vigorous activities, Kuwaiti boys performed more physical activity than the girls. A similar gender difference in physical activity level has been observed among Saudi adolescent children of same age group ${ }^{(21)}$. However, compared with Kuwaiti children, proportionately less Saudi boys (43.5\%) and girls (12.9\%) were fulfilling the criterion of moderate- to vigorousintensity physical activity for at least $1 \mathrm{~h} / \mathrm{d}^{(21)}$.

The gender difference in physical activity level among Kuwaiti children could be due to cultural reasons, where families may not encourage girls to take part in physical activities. Moreover, girls compared with boys generally have limited opportunities and facilities for physical activities, both inside and outside school. However, gender differences were also noted in the physical activities of adolescents in many other countries. For example, in a study encompassing twenty-four European countries, the percentage of young adolescents who were 
engaging in different types of physical activities for at least $1 \mathrm{~h} / \mathrm{d}$ ranged from $27 \%$ to $49 \%$ in boys and from $11 \%$ to $37 \%$ in girls ${ }^{(32)}$. Further, across the UK, it has been reported that a relatively higher proportion of boys than girls was active at almost every age, with an average of $32 \%$ of the boys and $24 \%$ of the girls meeting the recommended physical activity levels for young people ${ }^{(33)}$.

In the present study, we found that not only were girls less active, especially in vigorous activities, than boys, but girls also reported spending more time engaged in sedentary activities, such as watching TV and using a computer. The American Academy of Pediatrics has issued guidelines for recommended screen viewing time for children and adolescents of not exceeding $2 \mathrm{~h} / \mathrm{d}^{(29)}$. The present study revealed that almost all (>95\%) boys and girls spent more than $2 \mathrm{~h} / \mathrm{d}$ on screen time, with girls spending more time watching TV and using computers. Time spent in sedentary activities such as watching TV, listening to music, computer utilization and doing homework by adolescents has been reported for many countries. The study among Saudi adolescents reported that about $11 \%$ of girls and $16 \%$ of boys met the American Academy of Pediatrics' recommendations on daily screen time ${ }^{(21)}$, whereas a study among GreekCypriot children and adolescents reported that more than $50 \%$ spent less than $2 \mathrm{~h}$ watching TV daily ${ }^{(34)}$. In a study of over 1200 American children (8-16 years of age), about $48 \%$ of the boys and $38 \%$ of the girls reported watching TV for more than $2 \mathrm{~h} / \mathrm{d}$. Spending more time watching TV was positively associated with the prevalence of overweight and obesity in girls but not in boys ${ }^{(35)}$. It needs to be recognized that sedentary behaviours are associated with harmful health outcomes that are different from those attributable to physical inactivity ${ }^{(36)}$.

The present study also sought to assess the food habits of Kuwaiti adolescent children and examined the variation in food consumption between genders. The food intake patterns that are considered to be healthy include daily intake of breakfast, milk, fruit and vegetables. Skipping breakfast is a well-recognized unhealthy dietary behaviour and we also observed a significant negative association of the number of days of consumption of breakfast with BMI and waist circumference ${ }^{(20)}$. A similar association was also reported for Saudi adolescents ${ }^{(21)}$. The present study revealed that only about $28 \%$ of the boys and $18 \%$ of the girls consumed breakfast daily. A similar proportion of Saudi adolescents were also found not to be having a daily breakfast ${ }^{(21)}$. Although a significant proportion of these Kuwaiti adolescent children never or rarely (1-3 times/week) consumed milk, vegetables and fruit, a relatively higher proportion of males followed a healthier eating pattern (milk, vegetables and fruit consumed daily) than their female counterparts, a finding similar to that reported for Saudi adolescent children $^{(21)}$. On the other hand, the girls appeared to have significantly higher weekly mean intake frequencies of cakes/doughnuts and sweets than boys. Further, similar to the findings of the Saudi adolescents ${ }^{(21)}$, a significantly higher proportion of the girls reported consuming cakes/ doughnuts and sweets on more than $3 \mathrm{~d}$ /week than the boys. In contrast to the findings of the present study, female adolescents in Western countries were found to have healthier food intake patterns than their male counterparts ${ }^{(19)}$. This difference could be attributable to the differences in cultural norms related to body image in the Arab Gulf countries. For example, people in Kuwait were found to be more tolerant of persons who are overweight than people in Western countries ${ }^{(37)}$ and another study in Qatar reported nearly half of the study participants believed that men prefer plump women ${ }^{(38)}$.

Kuwaiti adolescents in our study reported having sugarsweetened drinks more frequently; nearly two-thirds of the boys (66\%) and girls (60\%) reported consuming them on more than $3 \mathrm{~d} /$ week. Similar to our findings, Saudi adolescent children also reported higher frequency of consumption with $67 \cdot 3 \%$ of the boys and $57 \cdot 4 \%$ of the girls having sugar-sweetened drinks on more than $3 \mathrm{~d} /$ week $^{(21)}$. The weekly mean frequency of intake of fast foods was similar between Kuwaiti boys and girls; in contrast, Saudi adolescent boys had higher mean frequency of intake of fast foods than girls ${ }^{(21)}$. But similar to Saudi adolescents ${ }^{(21)}$, relatively more boys (32\%) than girls $(26 \%)$ in the present study reported consuming fast foods on more than $3 \mathrm{~d} /$ week. Al-Hazzaa et al. ${ }^{(21)}$ in their study reported an inverse association of BMI with frequency of intake of fast foods and sugar-sweetened beverages among Saudi female adolescents.

The present study has a number of limitations. First, the data on physical activity and diet were collected using a self-reported questionnaire, which might have introduced some errors in estimation. Second, regarding dietary information, consumption of each of the selected foods was collected based on frequency per week without portion size. Nevertheless, a strength of the study was the use of a representative sample of public and private schoolchildren in Kuwait. A further strength of our study was that it used a validated and comprehensive physical activity questionnaire and used MET to calculate energy expenditure from physical activity.

\section{Conclusion}

The present study has generated important information which has value as reference and can be used as a basis from which policy can be developed. The data on physical activity and dietary pattern also clearly indicate that a large proportion of the Kuwaiti adolescents especially girls do not perform adequate physical activity, spend a high proportion of time performing sedentary activities and have unhealthy dietary habits. Considering the high prevalence of overweight and obesity, the present 
study findings emphasize the urgent need for suitable approaches designed to improve the situation of Kuwaiti adolescents by promoting more regular physical activities with a reduction in sedentary activities and improving healthy dietary behaviours.

\section{Acknowledgements}

Sources of funding: The authors are indebted to the Public Authority for Applied Education and Training (PAAET), Kuwait for financial support of this study. Conflicts of interest: The authors have no conflicts of interest. The funder (PAAET) had no role in the design, analysis or writing of this article. Authors' contributions: A.R.A.-H., H.M.A-H. and A.O.M. conceived the study design; A.R.A.-H., F.A.A.-A., M.A.A.-F. and B.I.A.-A. supervised data collection and data entry; F.A., A.A. and A.R.A.-H. conducted the data analysis and wrote the manuscript. All authors read, edited and approved the manuscript. Acknowledgements: The authors express their sincere thanks to the Ministry of Education and all schools for giving permission to conduct the study. They also thank the adolescents who participated in the study.

\section{References}

1. Wang Y \& Lobstein T (2006) Worldwide trends in childhood overweight and obesity. Int J Pediatr Obes 1, 11-25.

2. Dietz WH (2004) Overweight in childhood and adolescence. New Eng J Med 350, 855-857.

3. Daniels SR, Arnett DK, Eckel RH et al. (2005) Overweight in children and adolescents: pathophysiology, consequences, prevention, and treatment. Circulation 111, 1999-2002.

4. Office of the Surgeon General (2010) The Surgeon General's Vision for a Healthy and Fit Nation. Rockville, MD: US Department of Health and Human Services.

5. Chu NE, Wang DG \& Shieh SM (2001) Obesity, leptin and blood pressure among children in Taiwan: the Taipei Children's Heart Study. Am J Hypertension 14, 135-140.

6. Calcaterra V, Klersy C, Muratori T et al. (2007) Prevalence of metabolic syndrome (MS) in children and adolescents with varying degree of obesity. Clin Endocrinol (Oxf) 86 , 868-872.

7. Freedman DS, Zuguo M, Srinivasan SR et al. (2007) Cardiovascular risk factors and excess adiposity among overweight children and adolescents: the Bogalusa Heart Study. J Pediatr 150, 12-17.

8. Li C, Ford ES, Zhao G et al. (2009) Prevalence of pre-diabetes and its association with clustering of cardiometabolic risk factors and hyperinsulinemia among US adolescents: NHANES 2005-2006. Diabetes Care 32, 342-347.

9. Freedman DS, Khan LK, Serdula MK et al. (2005) Racial differences in the tracking of childhood BMI to adulthood. Obes Res 13, 928-935.

10. Must A, Jacques PF, Dallal GE et al. (1992) Long term morbidity and mortality of overweight adolescents: a follow-up of the Harvard Growth Study of 1992 to 1935. N Engl J Med 327, 1350-1355.

11. Reilly JJ \& Kelly J (2011) Long-term impact of overweight and obesity in childhood and adolescence on morbidity and premature mortality in adulthood: systematic review. Int J Obes (Lond) 35, 891-898.
12. Ministry of Health, Administration of Food and Nutrition (2010) Kuwait Nutrition Surveillance System 2005-2010 Report. Kuwait: Ministry of Health.

13. Stubbs CO \& Lee AJ (2004) The obesity epidemic: both energy intake and physical activity contribute. Med J Aust 181, 489-491.

14. Swinburn BA, Jolley D \& Kremer PJ (2006) Estimating the effects of energy imbalance on changes in body weight in children. Am J Clin Nutr 83, 859-863.

15. Naska A (2011) Eating out, weight and weight gain. A crosssectional and prospective analysis in the context of the EPIC-PANACEA study. Int J Obes (Lond) 35, 416-426.

16. Al-Isa AN (1997) Changes in body mass index (BMI) and prevalence of obesity among Kuwaitis 1980-1994. Int J Obes Relat Metab Disord 21, 1093-1099.

17. El-Bayoumy I, Shady I \& Lotfy H (2009) Prevalence of obesity among adolescents (10 to 14 years) in Kuwait. Asia Pac J Public Health 21, 153-159.

18. Sallis JF, Zakarian JM, Hovell MF et al. (1996) Ethnic, socioeconomic, and sex differences in physical activity among adolescents. J Clin Epidemiol 49, 125-134.

19. World Health Organization (2004) Young People's Health in Context: Health Behaviour in School-aged Children (HBSC) Study: International Report from the 2001/2002 Survey. Health Policy for Children and Adolescents no. 4. Copenhagen: WHO Regional Office for Europe.

20. Al-Haifi AR, Al-Fayez MA, Al-Athari BI et al. (2013) The relative contribution of physical activity, sedentary behaviors and dietary habits to the prevalence of obesity among Kuwaiti adolescents. Food Nutr Bull 34, 6-13.

21. Al-Hazzaa HM, Abahussain NA, Al-Sobayel HI et al. (2011) Physical activity, sedentary behaviors and dietary habits among Saudi adolescents relative to age, gender and region. Int J Behav Nutr Phys Act 8, 140.

22. Al-Hazzaa HM, Musaiger A; ATLS Research Group (2011) Arab Teens Lifestyle Study (ATLS): objectives, design, methodology and implications. Diabetes Metab Syndr Obes 4, 417-426.

23. Cole T, Bellizzi M, Flegal K et al. (2000) Establishing a standard definition of child overweight and obesity worldwide: international survey. BMJ 320, 1240-1243.

24. World Health Organization (2000) Obesity: Preventing and Managing the Global Epidemic. Report of WHO Consultation. WHO Technical Report Series no. 894. Geneva: WHO.

25. Ainsworth BE, Haskell WL, Whitt MC et al. (2000) Compendium of physical activity: an update of activity codes and MET intensities. Med Sci Sports Exerc 32, 9 Suppl., S498-S516.

26. Ridley K, Ainsworth BE, Olds TS et al. (2008) Development of a compendium of energy expenditure for youth. Int J Behav Nutr Phys Act 5, 45.

27. Janssen I \& Leblanc AG (2010) Systematic review of the health benefits of physical activity and fitness in schoolaged children and youth. Int J Behav Nutr Phys Act 7, 40.

28. World Health Organization (2010) Global Recommendation on Physical Activity for Health. Geneva: WHO Press.

29. American Academy of Pediatrics, Committee on Public Education (2001) American Academy of Pediatrics: Children, adolescents, and television. Pediatrics 107, 423-426.

30. Musaiger AO (2011) Overweight and obesity in Eastern Mediterranean region: prevalence and possible causes. J Obes 2011, 407237 .

31. Al-Nakeeb Y, Lyons M, Collins P et al. (2012) Obesity, physical activity and sedentary behavior amongst British and Saudi youth: a cross-cultural study. Int J Environ Res Public Health 9, 1490-1506.

32. Armstrong A \& Welson JR (2006) The physical activity patterns of European youth with reference to methods of assessment. Sports Med 36, 1067-1086.

33. Department of Health, Physical Activity, Health Improvement and Protection (2011) Start Active, Stay Active: A Report on 
Physical Activity from the Four Home Countries' Chief Medical Officers. London: Department of Health.

34. Loucaides CA, Jago R \& Theophanous M (2011) Physical activity and sedentary behaviours in Greek-Cypriot children and adolescents: a cross-sectional study. Int J Behav Nutr Phys Act 8, 90.

35. Crespo CJ, Smit E, Troiano RP et al. (2001) Television watching, energy intake, and obesity in US children. Arch Pediatr Adolesc Med 155, 360-365.
36. Tremblay MS, Colley RC, Saunders TJ et al. (2010) Physiological health implications of a sedentary lifestyle. Appl Physiol Nutr Metab 35, 725-740.

37. Al-Isa AN (1999) Dietary and socio-economic factors associated with obesity among Kuwaiti college men. $\mathrm{BrJ}$ Nutr 82, 369-374.

38. Musaiger AO, Shahbeek NE \& Al-Mannai M (2004) The role of social factors and weight status in ideal body-shape preferences as perceived by Arab women. J Biosoc Sci 36, 699-707. 